\title{
Speculative Bubbles: Conditions Of Creation And Explosion
}

\author{
Paraschos Maniatis, Athens University of Economics and Business, Greece
}

\begin{abstract}
This study is an attempt to illustrate the compatibility of financial bubbles, even under conditions of market efficiency and rational anticipations. The classical models of rational anticipations fail to describe a unique course of the price evolution of a financial due to the multiplicity of solutions to which they arrive. The approach of the bubble as a martingale can offer principles of approaching the bubbles, the possibility of creation and their eventual explosion, even under conditions of strong market efficiency and rational anticipations.
\end{abstract}

Keywords: financial bubbles, "backward-forward" analysis, Blanchard, Muth-Taylor approach, Martingale Terms approach

\section{INTRODUCTION}

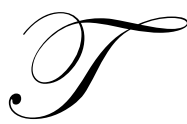

he financial bubbles are not something new in the financial history. The first famous bubble in the history exploded in the Netherlands - the 'Tulip bubble' - early in the $17^{\text {th }}$ century (November 1636 to January 1637). The bubble was followed by the collapse of its share and its issuing company. There followed the bubbles of the Company of Indies of John Law and the South Sea Company in 1720, and the chain is long, up to the great stock exchange bubble in the USA in 1929 (Galbraith, 1975). But the systematic study of the bubbles is relatively recent since the mathematical artillery for the bubbles study was not available to the economists. However, since the great Crash of 1929, the monetary thought has identified the origin of the financial bubbles in prolonged discrepancy between movements of the financial asset and its fundamentals.

The price movements of the assets traded in the financial markets, or in certain markets of goods, often give grounds to creation of speculative bubbles and prolonged volatile evolutions, which seem to negate any established wisdom concerning the "fundamentals" of the market. The nature of this approach itself reveals the difficulty of the subject. How can the fundamentals be defined and calculated? In the case of shares where the fundamentals are defined as the present value of the anticipated future values, how can the anticipations be theorized and formulated?

The bubbles are usually considered as results of the psychology of the market, its immanent uncertainty, decision difficulties, or cycles of euphoria and pessimism; and the work that many economists and economic historians have devoted to the speculative bubbles shows that the subject is loaded with intensive convictions and heavy preoccupations in which one can hardly distinguish elements of rationality. One can, however, pose the question of the reasons behind this loss of rationality and credibility of the market mechanisms, which have been established as explanatory factors for the price movements and the well-recognized foundations of the market behavior. And why the bubbles sometimes explode, while at other times they do not? Seeking to explain such extraordinary situations, the role of anticipations appears decisive. It is the framework of anticipations in which the speculative bubbles will be approached.

To have an idea as to how these bubbles can emerge, one has to start with the problem of the "multiplicity of the solutions of an equation of rational expectations". This perspective permits to approach the problem of emergence and, in a second stage, the development of such speculative bubbles. 


\section{THE MULTIPLICITY OF SOLUTIONS OF AN EQUATION OF RATIONAL ANTICIPATIONS}

The literature concerning the speculative bubbles under rational anticipations covers a wide range of financial assets, currency markets and money markets (inflationary bubbles). The conditions of emergence of inflationary bubbles reveal deep theoretical problems relating to the status of money - mean of conservation of purchasing power or simply a lubricant in the exchanges, or both - and to hyperinflation phenomena

One will show here that the price evolution, even in the case of preservation of equilibrium between supply and demand of the asset in the market, is not necessarily unique since the anticipations play an important role and they may cause disconnections of the price movements from those of the market fundamentals. This result will be established by referring to both the rational anticipations and to adaptive anticipations.

Several procedures for resolving the problem of the market equilibrium under rational anticipations have been developed. The problem arising in these studies is the multiplicity of the solutions of an equation of rational expectations. Here, one will follow the analyses of Muth (1961), Taylor (1977) and Fama (1991).

\section{II.1 The Problem Of Multiplicity Of Solutions And The Approach Of Muth-Taylor}

The illustration of this approach is given in the context of four equations representing the supply and demand in the goods and monetary markets posed by Muth. In all equations, the variables are logged and the coefficients are positive numbers. The symbol E stands for mathematical expectation, $\Omega$ for information available to all market agents, and the slash (/) for conditional statements.

The anticipated price formed in period $t-1$ for the periods $t$ and $t+1$ are supposed to be rational, that is ${ }_{t-1} P_{t}^{\alpha}$ $=\mathrm{E}\left(\mathrm{P}_{\mathrm{t}} / \Omega_{\mathrm{t}-1}\right)$ and ${ }_{\mathrm{t}-1} \mathrm{P}_{\mathrm{t}+1}^{\alpha}=\mathrm{E}\left(\mathrm{P}_{\mathrm{t}+1} / \Omega_{\mathrm{t}-1}\right)$, which are traditionally denoted by $\mathrm{E}_{\mathrm{t}-1} \mathrm{P}_{\mathrm{t}}$ and $\mathrm{E}_{\mathrm{t}-1} \mathrm{P}_{\mathrm{t}+1}$.

The equation of aggregate demand for goods is formulated as

$y_{t}^{d}=-\lambda_{1}\left(i_{t}-\left(E_{t-1} P_{t+1}-E_{t-1} P_{t}\right)\right)+\lambda_{2}\left(m_{t}-P_{t}\right)+\varepsilon_{1, t}$

It relates the reactions of demand to the movements of the real rate of interest (nominal rate $i_{t}$ minus anticipated price evolution) and to real liquids $\left(\mathrm{m}_{\mathrm{t}}-\mathrm{p}_{\mathrm{t}}\right)$ held by agents. Further, it is affected by an uncertainty element - the stochastic variable $\varepsilon_{1, \mathrm{t}}$.

The aggregate supply for goods is formulated as

$\mathrm{y}_{\mathrm{t}}^{\mathrm{s}}=\varphi_{0}+\varphi_{1}\left(\mathrm{~m}_{\mathrm{t}}-\mathrm{P}_{\mathrm{t}}\right)+\varepsilon_{2, \mathrm{t}}$

For reasons of simplicity, it is supposed to be affected by the real liquid assets only.

The demand for money

$\mathrm{m}_{\mathrm{t}}^{\mathrm{d}}=\mathrm{y}_{\mathrm{t}}+\mathrm{P}_{\mathrm{t}}-\alpha_{1} \mathrm{i}_{\tau}+\alpha_{2}\left(\mathrm{~m}_{\mathrm{t}}-\mathrm{P}_{\mathrm{t}}\right)+\varepsilon_{3, \mathrm{t}}\left(\alpha_{2} \leq 0\right)$

depends traditionally on the volume $y_{t}$ of transactions, on the price $\mathrm{P}_{t}$, on the rate of interest $\mathrm{i}$ and on the real liquid assets $m_{t}-P_{t}$.

The supply of money is supposed to be exogenously determined and constant

$\mathrm{m}_{\mathrm{t}}^{\mathrm{s}}=\mathrm{m}$

It is supposed that the variables $\varepsilon_{1}, \varepsilon_{2}, \varepsilon_{3}$ are independent, normally distributed stochastic variables, each one having zero expectation and with variance-covariance matrix bounded and non-singular. 
Given the above equations, one can easily see that the solution of the equation describing the price evolution is not unique and that the non-uniqueness of the price evolution is compatible with state of equilibrium in the goods and money markets. By elementary substitutions, it is obtained the reduced linear equation

$\mathrm{E}_{\mathrm{t}-1} \mathrm{P}_{\mathrm{t}+1}=\mathrm{E}_{\mathrm{t}-1} \mathrm{P}_{\mathrm{t}}+\delta_{1} \mathrm{P}_{\mathrm{t}}+\delta_{0}+\mathrm{u}_{\mathrm{t}}$

$\delta_{1}=\left(1 / \alpha_{1}\right)\left(1-\alpha_{2}\right)+\lambda_{2}\left(1 / \lambda_{1}\right)-\varphi_{1}\left[\left(1 / \alpha_{1}\right)+\left(1 / \lambda_{1}\right)\right]$

$\delta_{0}=\varphi_{0}\left[1+\alpha_{1}\left(1 / \lambda_{1}\right)\right]-\delta_{1} \mathrm{~m}$ and

$\mathrm{u}_{\mathrm{t}}=\varepsilon_{1, \mathrm{t}}-\alpha_{1}\left(1 / \lambda_{1}\right) \varepsilon_{2, \mathrm{t}}+\left[1+\alpha_{1}\left(1 / \lambda_{1}\right)\right] \varepsilon_{3, \mathrm{t}}$

The term $u_{t}$ in equation (II.1.5) is a stochastic variable with zero mean and bounded variance. In this way, one obtains the determination of the price $\mathrm{P}_{t}$ by the anticipated price in the period $t-1$ for the periods $t$ and $t+1$ by the money offer $m$ and the stochastic elements $\varepsilon$. In order to determine $\mathrm{P}_{\mathrm{t}}$ Taylor postulates

$\mathrm{P}_{\mathrm{t}}=\mathrm{P}_{\mathrm{c}}+\Sigma \pi_{\mathrm{i}} \mathrm{u}_{\mathrm{t}-\mathrm{i}}, \mathrm{i}=0,1, \ldots \infty$

where $\pi_{1}$ are parameters to be determined. This equation means that the prices fluctuate around a base level $\mathrm{P}_{\mathrm{c}}$ under the affection of the uncertainty elements included in $\mathrm{u}_{\mathrm{t}}$.

Further, since $\mathrm{E}_{\mathrm{t}-1} \mathrm{P}_{\mathrm{t}}=\mathrm{P}_{\mathrm{c}}+\sum \pi_{\mathrm{i}} \mathrm{u}_{\mathrm{t}-\mathrm{i}}$ and $\mathrm{E}_{\mathrm{t}-1} \mathrm{P}_{\mathrm{t}+1}=\mathrm{P}_{\mathrm{c}}+\sum \pi_{\mathrm{i}} \mathrm{u}_{\mathrm{t}+1-\mathrm{i}}, \mathrm{i}=2,3, \ldots \ldots$ one obtains by substitution in the reduced equation (II.1.5)

$\mathrm{P}_{\mathrm{c}}=-\delta_{0}\left(1 / \delta_{1}\right), \pi_{0}=-\left(1 / \delta_{1}\right)$ and $\pi_{\mathrm{i}+1}=\left(1+\delta_{1}\right) \pi_{\mathrm{i}}, \mathrm{i}=1,2, \ldots \ldots$

The above recursive forms show that there is indeterminacy of $\pi_{1}$, hence of $\pi_{2}$ etc. Substitution of the above expressions in the price equation (II.5) gives

$\mathrm{P}_{\mathrm{t}}=\left(1+\delta_{1}\right) \mathrm{P}_{\mathrm{t}-1}+\delta_{0}-\left(1 / \delta_{1}\right) \mathrm{u}_{\mathrm{t}}+\left[\pi_{1}-\left(1+\delta_{1}\right)\left(1 / \delta_{1}\right)\right] \mathrm{u}_{\mathrm{t}-1}$

which is an $\operatorname{ARMA}(1,1)$ process.

But every admissible value of $\pi_{1}$ modifies the trajectory of the price where there exists a multiplicity of solutions. According to the above analysis, it is plausible to conclude that any model including anticipations rational, adaptive, etc. - leads to indeterminacy of the solution. Now comes the contribution of Blanchard.

\section{II.2 The "Backward-Forward" Analysis Of Blanchard}

In Blanchard's model (Blanchard, 1979) of "overlapping generations", it is supposed that the life duration of every agent consists of two periods. In the first period, the agent is specified as "young" and he is endorsed with a consumable good, which he consumes and can therefore spare his money. In the same period, the agents, which are in the second period the "old" agents, propose to the "young" agents money against goods. In this very simple context, the demand for money is supposed to be a function of anticipated inflation rate:

$\left(m_{t}-P_{t}\right)^{d}=-\alpha\left({ }_{t} P_{t+1}^{\alpha}-P_{t}\right)$

The coefficient $\alpha$ can be positive or negative depending on the reaction of the purchases before an anticipated inflation. The money supply

$\left(\mathrm{m}_{\mathrm{t}}-\mathrm{P}_{\mathrm{t}}\right)^{\mathrm{s}}=\mathrm{m}_{\mathrm{t}}$

is fixed by the authorities and the "old" agents. In equilibrium it holds 
$\left(m_{t}-P_{t}\right)^{d}=\left(m_{t}-P_{t}\right)^{s}$

The anticipations are supposed to be rational: ${ }_{\mathrm{t}} \mathrm{P}_{\mathrm{t}+1}^{\alpha}=\mathrm{E}\left(\mathrm{P}_{\mathrm{t}+1} / \Omega_{\mathrm{t}}\right)$. A simple calculation shows that the equilibrium equation is:

$\mathrm{P}_{\mathrm{t}}=\left[\mathrm{m}_{\mathrm{t}}+\alpha \mathrm{E}\left(\mathrm{P}_{\mathrm{t}+1} / \Omega_{\mathrm{t}}\right)\right] /(1+\alpha)$

In order to determine the price movement, Blanchard postulates a model of the type

$\mathrm{P}_{\mathrm{t}}=\Sigma \alpha_{\mathrm{i}} \mathrm{m}_{\mathrm{t}-\mathrm{i}}+\mathrm{bm}_{\mathrm{t}}+\sum \mathrm{c}_{\mathrm{i}} \mathrm{E}\left(\mathrm{P}_{\mathrm{t}+\mathrm{i}} / \Omega_{\mathrm{t}}\right) \quad \mathrm{i}=1,2, \ldots \infty$

with $\alpha_{i}, b, c_{i}$ such as to satisfy the above equation and under the assumption that the sums converge. This specification of the prices movement supposes that the prices depend only on past and future money supply. Taking into consideration the basic property of conditional expectation $\mathrm{E}\left[\mathrm{E}\left(\mathrm{m}_{\mathrm{t}+\mathrm{i}+1} / \Omega_{\mathrm{t}+1}\right) / \Omega_{\mathrm{t}}\right]=\mathrm{E}\left(\mathrm{m}_{\mathrm{t}+\mathrm{i}+1} / \Omega_{\mathrm{t}}\right)$, it results in

$\mathrm{E}\left(\mathrm{P}_{\mathrm{t}+1} / \Omega_{\mathrm{t}}\right)=\Sigma \alpha_{\mathrm{i}} \mathrm{m}_{\mathrm{t}+1-\mathrm{i}}+\mathrm{bE}\left(\mathrm{m}_{\mathrm{t}+1} / \Omega_{\mathrm{t}}\right)+\sum \mathrm{c}_{\mathrm{i}} \mathrm{E}\left(\mathrm{m}_{\mathrm{t}+1+\mathrm{i}} / \Omega_{\mathrm{t}}\right), \mathrm{i}=1,2, \ldots \ldots \ldots \infty$

Substituting this expression in the price equation in equilibrium and identifying term- by-term, one obtains the coefficients:

$\alpha_{1}=[b(1+\alpha)-1] / \alpha$

$\alpha_{i+1}=(1+\alpha) \alpha_{1} / \alpha, i=1,2, \ldots \ldots \ldots$

$c_{1}=b \alpha /(1+\alpha)$

$c_{i+1}=\alpha c_{i} /(1+\alpha), i=1,2, \ldots \ldots \ldots$

The above expressions show that there exists as many solutions as the values attributable to the parameter $b$.

But every solution can be expressed as a weighted sum, which exhibits a "backward" solution for $b=0$ and $c_{i}=0$ for every I; that is,

$\mathrm{P}^{\mathrm{B}}{ }_{\mathrm{t}}=-\alpha^{-1} \Sigma[(1+\alpha) / \alpha]^{\mathrm{i}} \mathrm{m}_{\mathrm{t}-\mathrm{i}-1}, \mathrm{i}=0,1, \ldots \infty$

(the prices depend only on the past money supplies), or a "forward" solution for $b=(1+\alpha)^{-1}$ and for $\alpha_{i}=0$, for every I; that is,

$\mathrm{P}_{\mathrm{t}}^{\mathrm{F}}=(1+\alpha)^{-1}\left\{\mathrm{~m}_{\mathrm{t}}+\Sigma\left[\alpha(1+\alpha)^{-1}\right]^{\mathrm{i}} \mathrm{E}\left(\mathrm{m}_{\mathrm{t}+\mathrm{i}} / \Omega_{\mathrm{t}}\right)\right\}, \mathrm{i}=1,2, \ldots \infty$

(The prices depend only on the present and the future value of the money supplies.) Every solution, hence, can be written as:

$\mathrm{P}_{\mathrm{t}}=\lambda \mathrm{P}^{\mathrm{B}}{ }_{\mathrm{t}}+(1-\lambda) \mathrm{P}_{\mathrm{t}}^{\mathrm{F}}$ with $\lambda=1-\mathrm{b}(1+\alpha)$

The above equation shows that the parameter $\mathrm{b}$ can be specified so as to exist a backward and a forward solution, but at the same time it over-determines the general solution. Again, here the indeterminacy is caused by the presence of anticipated values in the equilibrium equation; in every period $t$ both $\mathrm{P}_{\mathrm{t}}$ and ${ }_{\mathrm{t}} \mathrm{P}_{\mathrm{t}+1}^{\alpha}$ determine together the equilibrium in the money market. Besides, in the backward solution a permanent increase of the money supply starting in period $t$ would increase the real value of the money, $\mathrm{m}_{\mathrm{t}} / \mathrm{P}_{\mathrm{t}}$, without affecting the price level, while in the forward solution the value of $\mathrm{m}_{\mathrm{t}} / \mathrm{P}_{\mathrm{t}}$ is not affected. The behavior of the agents depends on the choice of solution.

The above analysis revealed the multiplicity of equilibrium solutions of a dynamic model of rational anticipations. In order to reduce the number of solutions in the Blanchard's model, one could impose criteria of 
optimality, coherence, stationarity, etc., but none of them seems convincing since they simply transfer the initial problem without solving it. If the agents lived too much, one could assume that the selection of an optimal plan is governed by the principle of maximization of the utility in an infinite time horizon; but in the framework of Blanchard's analysis, this assumption cannot be valid since for an infinite time, there is no "young" and "old".

The forward solution can be accepted since it satisfies the coherence criterion; but in the case of backward solution, the model allows the prices to react to current money supply variations with delay, which cannot be a plausible result.

Finally, so far as the stationarity criterion is concerned, if the fluctuations of money supply $\mathrm{m}_{\mathrm{t}}$ are not important $\left(\mathrm{m}_{\mathrm{t}}\right.$ is of small variance), the variance of prices shares also the same property. But here again, new problems arise: Can this assumption result to a unique solution? Not necessarily. The crucial factor is the elasticity of price in regard to the anticipations

$\mathrm{e}=|\alpha /(1+\alpha)|$

If $\mathrm{e}<1$, that is if $\alpha>-1 / 2$, it is clear that only the forward solution is stationary; if $\mathrm{e}>1$, then only the backward solution is stationary. To show that suppose that the money supply follows an AR(1) scheme

$\mathrm{m}_{\mathrm{t}}=\rho \mathrm{m}_{\mathrm{t}-1}+\eta_{\mathrm{t}}$

with $|\rho|<1$ (the $\eta_{\mathrm{t}}$ are independent, identically distributed stochastic variables with $\left.\mathrm{E}\left(\mathrm{m}_{\mathrm{t}+\mathrm{i}} / \Omega_{\mathrm{t}}\right)=\rho^{\mathrm{i}} \mathrm{m}_{\mathrm{t}}\right)$. If $\rho$ is small enough so that $|\alpha \rho /(1+\alpha)|<1$, then for $i=0,1, \ldots \ldots \infty$

$\mathrm{P}_{\mathrm{t}}^{\mathrm{F}}=(1+\alpha)^{-1} \Sigma[\alpha \rho /(1+\alpha)]^{\mathrm{i}} \mathrm{m}_{\mathrm{t}}=[1+\alpha(1-\rho)]^{-1} \mathrm{~m}_{\mathrm{t}}$

and, hence, $\mathrm{P}_{\mathrm{t}}^{\mathrm{F}}$ is stationary. Consequently, the property of stationarity alone does not ensure uniqueness of solution. For uniqueness, one could impose the constraint that the variance of the price is minimal, but what is the meaning of such a requirement for the markets?

\section{APPROACH IN MARTINGALE TERMS}

The use of martingales allows both to shed some light into the problem of discrepancy between the price of a financial asset and its fundamentals in terms of rational anticipations and to formulate a range of possibilities to emerge a speculative bubble.

\section{III.1 General Results}

Consider a model of market equilibrium of the type

$\mathrm{P}_{\mathrm{t}}=\mu \mathrm{E}\left(\mathrm{P}_{\mathrm{t}+1} / \Omega_{\mathrm{t}}\right)+(1-\mu) \omega_{\mathrm{t}}, \mu<1$

$\omega$ : stochastic variable with bounded mean and variance.

This equation is of the same concept to the ones of rational anticipations since it relates the price of a period $t$ to the anticipated price of period $t+1$. By forward substitutions in (III.1), it results

$\mathrm{P}_{\mathrm{t}}=\mu^{2} \mathrm{E}\left(\mathrm{P}_{\mathrm{t}+2} / \Omega_{\mathrm{t}}\right)+(1-\mu)\left[\omega_{\mathrm{t}}+\mu \mathrm{E}\left(\omega_{\mathrm{t}+1} / \Omega_{\mathrm{t}}\right)\right]$

and by successive forward substitutions, it obtained the forward solution:

$\mathrm{P}_{\mathrm{t}}=\mu^{\mathrm{N}} \mathrm{E}\left(\mathrm{P}_{\mathrm{t}+\mathrm{N}} / \Omega_{\mathrm{t}}\right)+(1-\mu) \Sigma \mu^{\mathrm{i}} \mathrm{E}\left(\omega_{\mathrm{t}+\mathrm{i}} / \Omega_{\mathrm{t}}\right), \mathrm{i}=0,1, \ldots, \mathrm{N}-1$ 
This solution has no meaning except if $\mathrm{E}\left(\mathrm{P}_{\mathrm{t}+\mathrm{N}} / \Omega_{\mathrm{t}}\right)$ is known; but this term can be neglected if the prices increase slowly so that $\mu^{\mathrm{N}} \mathrm{E}\left(\mathrm{P}_{\mathrm{t}+\mathrm{N}} / \Omega_{\mathrm{t}}\right) \rightarrow 0$ as $\mathrm{N}->\infty$ (transversal condition). In the opposite case, a fast price increase will give to the market grounds to anticipate further increments and the price will be explosive as a result of selffulfilled prophecy. Therefore, neglecting the term $\mathrm{E}\left(\mathrm{P}_{\mathrm{t}+\mathrm{N}} / \Omega_{\mathrm{t}}\right)$, the solution becomes

$\mathrm{P}_{\mathrm{t}}=(1-\mu) \Sigma \mu^{\mathrm{i}} \mathrm{E}\left(\omega_{\mathrm{t}+\mathrm{i}} / \Omega_{\mathrm{t}}\right), \mathrm{i}=0,1, \ldots, \mathrm{N}-1$

The above equation shows that even this approach is conditioned by the market anticipations on the future price evolution.

But advancement can be achieved if one considers the bubble as a martingale. It can be shown that if (III.3) is an equilibrium solution for $\mathrm{P}_{t}$, then any $\mathrm{P}_{t}{ }_{t}$ such as $\mathrm{P}^{\prime}{ }_{t}=\mathrm{P}_{t}+\mu^{-t} \mathrm{~A}_{t}$ is also an equilibrium solution if $\mathrm{A}_{t}$ is a martingale, i.e. if $\mathrm{E}\left(\mathrm{A}_{\mathrm{t}} / \Omega_{\mathrm{t}-1}\right)=\mathrm{A}_{\mathrm{t}-1}$.

For in this case $\mu \mathrm{E}\left(\mathrm{P}^{\prime}{ }_{t+1} / \Omega_{\mathrm{t}}\right)=\mu \mathrm{E}\left(\mathrm{P}_{\mathrm{t}+1}+\mu^{-\mathrm{t}-1} \mathrm{~A}_{\mathrm{t}+1} / \Omega_{\mathrm{t}}\right)=\mu \mathrm{E}\left(\mathrm{P}_{\mathrm{t}+1} / \Omega_{\mathrm{t}}\right)+\mu^{-\mathrm{t}} \mathrm{E}\left(\mathrm{A}_{\mathrm{t}+1} / \Omega_{\mathrm{t}}\right)=\mu \mathrm{E}\left(\mathrm{P}_{\mathrm{t}+1} / \Omega_{\mathrm{t}}\right)+\mu^{-\mathrm{t}} \mathrm{A}_{\mathrm{t}}$.

But $P_{t}$ being an equilibrium solution it results that $\mu \mathrm{E}\left(\mathrm{P}^{\prime}{ }_{t+1} / \Omega_{t}\right)=\mathrm{P}_{\mathrm{t}}-(1-\mu) \omega_{\mathrm{t}}+\mu^{-t} \mathrm{~A}_{\mathrm{t}}=\mathrm{P}_{\mathrm{t}^{\prime}}-(1-\mu) \omega_{\mathrm{t}}$. Therefore, the solution

$\mathrm{P}_{\mathrm{t}}=\mu \mathrm{E}\left(\mathrm{P}_{\mathrm{t}+1} / \Omega_{\mathrm{t}}\right)+(1-\mu) \omega_{\mathrm{t}}$

is also an equilibrium solution. This result plays an important role in the study of the financial bubbles.

\section{III.2 "Forward" Solution And Fundamentals Of A Share In The Stock Exchange}

Consider a share, the return of which is calculated via its value $P_{t}$ and its dividend $d_{t} r_{t}=\left(P_{t+1}-P_{t}+d_{t}\right) / P_{t}$. Under the hypothesis that the agent is risk neutral and that the market is efficient so that all arbitrage opportunities have been exploited, the expected return $\mathrm{r}_{\mathrm{t}}=\mathrm{E}\left(\mathrm{r}_{\mathrm{t}} / \Omega_{\mathrm{t}}\right)$ will be equal to the market return $\mathrm{r}$ (supposed constant). Here $\Omega_{\mathrm{t}}$ denotes the totality of information in the market possessed by all the agents. This hypothesis is stronger than that of market efficiency since the latter can refer to a subset of the information shared by all agents. Since the market is efficient, it holds that $\mathrm{P}_{t+1}=\mathrm{E}\left(\mathrm{P}_{\mathrm{t}+1} / \Omega_{\mathrm{t}}\right)$ and the equation of the share return becomes $r \mathrm{P}_{t}=\mathrm{E}\left(\mathrm{P}_{\mathrm{t}+1} / \Omega_{\mathrm{t}}\right)-\mathrm{P}_{\mathrm{t}}+\mathrm{d}_{\mathrm{t}}$, which can be written as $\mathrm{P}_{t}=\theta \mathrm{E}\left(\mathrm{P}_{\mathrm{t}+1} / \Omega_{\mathrm{t}}\right)+\theta \mathrm{d}_{\mathrm{t}}, \theta=(1+\mathrm{r})^{-1}<1$. The forward solution of the above is

$\mathrm{P}^{*}{ }_{\mathrm{t}}=\Sigma \theta^{\mathrm{j}+1} \mathrm{E}\left(\mathrm{d}_{\mathrm{t}+\mathrm{j}} / \Omega_{\mathrm{t}}\right), \quad \mathrm{i}=0,1, \ldots \infty$

The equation shows that the value of the share is the present value of the anticipated dividends. This means that the price of the asset is determined by the fundamentals of the asset as the financial analysts offer them. But after (III.5), any equation of the form $\mathrm{P}_{\mathrm{t}}=\mathrm{P}^{*}{ }_{\mathrm{t}}+\mathrm{c}_{\mathrm{t}}$ with $\mathrm{E}\left(\mathrm{c}_{\mathrm{t}+1} / \Omega_{\mathrm{t}}\right)=\mathrm{c}_{\mathrm{t}} \theta^{-1}$ is also a solution since the condition $\mathrm{E}\left(\mathrm{c}_{\mathrm{t}+1} / \Omega_{\mathrm{t}}\right)=\mathrm{c}_{\mathrm{t}} \theta^{-1}$ indicates that $\mathrm{c}_{\mathrm{t}}$ is a martingale. Therefore, if $\mathrm{P}_{\mathrm{t}}-\mathrm{P}^{*}{ }_{\mathrm{t}}=\mathrm{c}_{\mathrm{t}}$ is a martingale, the price $\mathrm{P}_{\mathrm{t}}$ of the financial asset can deviate from its "fundamental" value $\mathrm{P}^{*}{ }_{t}$ without contradicting the condition of market efficiency. This consideration gives grounds to think that the possibility of a bubble is not an antinomy to an efficient market. Further, the deviation $\mathrm{c}_{\mathrm{t}}=\mathrm{P}_{\mathrm{t}}-\mathrm{P}^{*}{ }_{\mathrm{t}}$, once appeared, can increase indefinitely since $\theta^{-1}>1$ and the bubble becomes explosive. Up to this point and in this framework, the bubble remains a possibility and the condition to come to existence is that the agents think that the price will increase in the future, while the fundamentals do not justify such a continuous perspective. The condition $\mathrm{E}\left(\mathrm{c}_{\mathrm{t}+1} / \Omega_{\mathrm{t}}\right)=\mathrm{c}_{\mathrm{t}} \theta^{-1}$ implies that as $\mathrm{n}->\infty$

$\lim \mathrm{E}\left(\mathrm{c}_{\mathrm{t}+\mathrm{n}} / \Omega_{\mathrm{t}}\right)=\left\{+\infty\right.$ if $\mathrm{c}_{\mathrm{t}}>0 ;-\infty$ if $\left.\mathrm{c}_{\mathrm{t}}<0\right\}$

although the probability of a bubble explosion increases with time, the anticipated value of the share does not cease to increase. 


\section{III.3 Conditions Of Development Of Speculative Bubbles Under Rational Anticipations}

One can distinguish several forms of rational bubbles. Consider, for example, the case that the term $c_{t}$ takes in the value $(\theta \pi)^{-1} c_{t-1}+\mu_{t}$ with probability $\pi$ and the value $\mu_{t}$ with probability $1-\pi$, under the condition $E\left(\mu_{t} / \Omega_{t-1}\right)$, that is under $\mathrm{E}\left(\mathrm{c}_{\mathrm{t}+1} / \Omega_{\mathrm{t}}\right)=\mathrm{c}_{\mathrm{t}} \theta^{-1}$. Such a situation has, in each period, probability $\pi$ for a bubble not to explode and 1- $\pi$ to explode. The mean duration of the situation is $(1-\pi)^{-1}$. So long as this situation exists, the returns on the share will be higher than $r$, which compensates the risk of capital losses attached to the possibility of a bubble explosion.

Consider now another situation in which the remuneration $\mathrm{d}_{\mathrm{t}}$ of a share is 1 in the 'state of nature I' and 0 in the 'state of nature II'. Suppose that in period t, one is in the state I and that this state is reproduced from period to period with probability $\pi$; then the fundamental value of the share is

$\mathrm{P}^{*}{ }_{\mathrm{t}}=\Sigma \theta^{\mathrm{j}+1} \mathrm{E}\left(\mathrm{d}_{\mathrm{t}+\mathrm{j}} / \Omega_{\mathrm{t}}\right)=\Sigma \theta^{\mathrm{j}+1} \pi^{\mathrm{j}}=\theta(1-\theta \pi)^{-1}, \mathrm{i}=0,1, \ldots \infty$

This value remains constant during the state of nature I. However, it is possible that the price of the share exceeds the value $\mathrm{P}_{\mathrm{t}}$ because of the anticipations of the agents during the state of nature $\mathrm{I}$, as illustrates the following example: in every period $\mathrm{t}$, the bubble has a value $\mathrm{c}_{\mathrm{t}}=\mathrm{c}_{0}$ and future values in $\mathrm{t}+\mathrm{j}$

$c_{t+j}=(\theta \pi)^{-1} c_{t+j-1}(j=1,2, \ldots)$

if the market is in the state of nature I and

$\mathrm{c}_{\mathrm{t}+\mathrm{j}}=0$ otherwise.

This means that during the state of nature $\mathrm{I}$, the price of the share exceeds the fundamental value connected with $c_{t}=c_{o}$. The price increases and at the end of state of nature I will be simultaneous deflation of the fundamental value and explosion of the bubble.

\section{CONCLUSIONS}

The anticipations of the financial agents play an inextricable role in the bubbles formation and the possibility that they eventually explode, even in conditions of market efficiency and rational anticipations. The models of rational anticipations involve parameters, which result to multiplicity of solutions, and they eventually fail to explain the conditions of bubbles creation.

The martingale approach offers the possibility of strong discrepancies between the price of a financial asset and its fundamentals, which may or may not drive the bubble to explosion. However, this treatment is formal and partial; what conditions could prohibit the emergence of a bubble and which conditions favor them? According to the above analysis, if the price of a share increases at a rate inferior to the discounted rate $\theta\left(\lim \theta^{n} \mathrm{E}\left(\mathrm{P}_{\mathrm{t}+\mathrm{n}} / \Omega_{\mathrm{t}}\right)=0, \mathrm{n}\right.$ $>\infty$ ), then its discounted ultimate price (its resale value in a very remote time) has but a negligible importance. The share's value will be exactly equal to the discounted value of the anticipated future dividends; ie to the fundamental value, and there is no room for bubble emergence. But this result is doubtful since the only reason for retaining a share, which is under-valuated in relation to its fundamental, is to expect profit from resale of the share. Moreover, an asset, the price of which is fixed in a future date, cannot create a bubble. Finally a crucial problem, often mystified in the financial literature, is the exact valuation fundamentals; ie that the emergence of a bubble is more probable in the measure that the fundamentals of the assets are not easily and/or uniquely identifiable.

\section{AUTHOR INFORMATION}

Paraschos Maniatis served as a faculty member at Wichita State University, USA University of Missouri-Rolla, USA, Truman State University, USA, University of Thessaly, Greece, University of Aegean, Greece. Presently he serves the faculty of Athens University of Economics and Business in the field of quantitative methods. He is a professional mechanical, electrical and a civil engineer and a member of the Technical Chamber of Commerce Greece. He has extensively published in international refereed journals and participated in conferences. 


\section{BIBLIOGRAPHY}

1. Baily, M.J. (1972) National Income and the Price Level, Tokyo: McGraw -Hill

2. Blanchard, O.J. (1979) Backward and forward solutions for economies with rational expectations, American Economic Review 69, pp. 114-119

3. Chatfield. C. (1996) The Analysis of Time Series, London: Chapman \& Hall/CRC

4. $\quad$ Fama, E. (1991) Efficient Capital Market Prices, Journal of Business, 38, pp. 1575-617

5. $\quad$ Galbraith, J.K. (1976) Money, Where it came, Where it went, Middlessex: Pelican books

6. Muth, J. (1961) Rational Expectations and the Theory of Price Movements, Econometrica, 29 pp. 315-335

7. Papoulis, A. (1965) Probability, Random Variables and Stochastic Processes, New York: McGraw-Hill

8. Taylor, J.B. (1977) Conditions for unique solutions in stochastic macroeconomic models with rational expectations, Econometrica, 45, pp. 1377-1385

\section{NOTES}

